\title{
Sierra Foothill REC: Quantifying IPM benefits in rangeland systems
}

\section{There's a strong scientific case that integrated pest management strategies for rangeland weeds are effective - yet adoption of these practices on rangeland is extremely low. How come? \\ One likely reason, says Jeremy James, director of Sierra Foothill Research and Extension Center (SFREC), is that it's unclear whether investing in reducing weed populations makes financial sense.}

"We have a good idea that invasive plants have negative ecological impacts - but what we surprisingly do not know is if there is actually any economic cost of having weeds on rangelands," James said.

A national assessment of rangeland integrated pest manage-

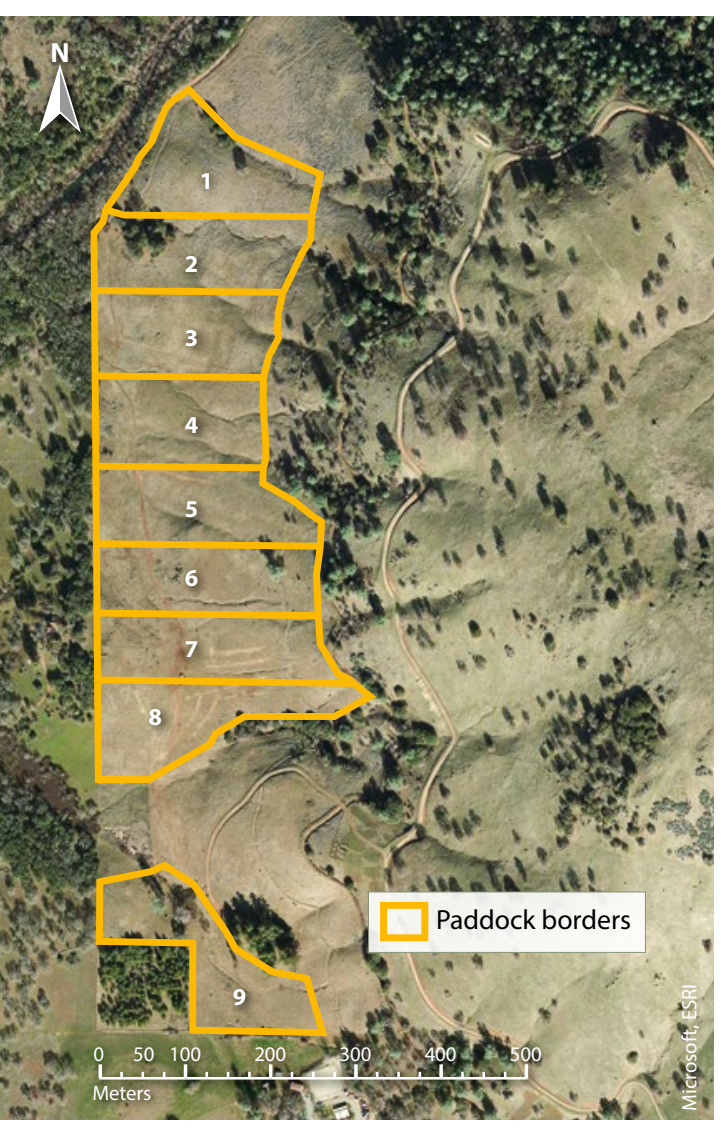

The 13 test paddocks (nine of which are shown here) enclose 5 acres each and are infested with medusahead to varying degrees - from $11 \%$ to $50 \%$ coverage. ment strategies like targeted grazing, seeding of desirable plants, prescribed fire and the use of selective herbicides found abundant evidence that these practices work (Sheley et al. 2011). However, the same study also found that that these practices are little-used - in part because of the difficulty of assessing their economic benefit.

To better understand the economic case for weed management, James and a team of researchers - including Tehama County livestock, range and natural resources advisor Josh Davy, Stanislaus County range and natural resources advisor Theresa Becchetti, Shasta County livestock, range and natural resources advisor Larry Forero and UC Davis Plant Science professor Emilio Laca - are running a series of experiments at SFREC.

Beginning in 2013, the team manipulated pastures to have different degrees of weediness, measured by the percentage of land infested with medusahead, a common rangeland weed. After 3 years, they had developed a series of 13 experimental 5-acre paddocks, with medusahead coverage ranging

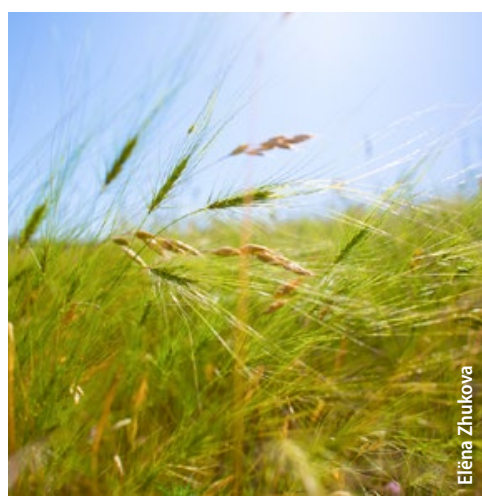

Medusahead (in green, above) is an aggressive invasive annual grass that is unpalatable to livestock for most of its life cycle. from $11 \%$ to $50 \%$.

This spring, the researchers stocked the pastures with steers from March through May and evaluated how weight gain varied with weed coverage.

Results from this first season of tests indicate that weight gain does indeed suffer as weediness increases: for every $10 \%$ increase in weed cover, total weight gain was reduced by roughly 30 pounds per acre - a reduction in market value of $\$ 30$ to $\$ 50$ per acre at current prices.

"For beef cattle production, those numbers are right in the middle of being something that might pencil out to treat," said James. "They're not going to cause ranchers to go out of business, but at the same time they're not negligible."

The study is scheduled to continue for at least another 2 years. The team will replicate the spring grazing study and also assess the effects of weeds at other times of year, James said.

The project is part of a collection of studies funded by the U.S. Department of Agriculture that aims to quantify the value of the many ecosystem services that rangelands can provide. Some of these, like the effect of weeds on cattle weight gain, can be directly quantified in economic terms. Others - such as the provision of habitat to support biodiversity or the benefits that healthy soil can provide for groundwater infiltration - may be more difficult to value but may still be desirable for ranchers to support. The overall goal of the project, James said, is to document the full suite of benefits that investments in rangeland management can deliver. CA

- Jim Downing

\section{Reference}

Sheley RL, James JJ, Rinella MJ, et al. 2011. Invasive plant management on anticipated conservation benefits: A scientific assessment. Chapter 7. In: Briske DD (ed.). Conservation Benefits of Rangeland Practices: Assessment, Recommendations, and Knowledge Gaps. US Department of Agriculture, Natural Resources Conservation Service. bit.ly/2C1H0s2. 